\title{
Sistema Punt
}

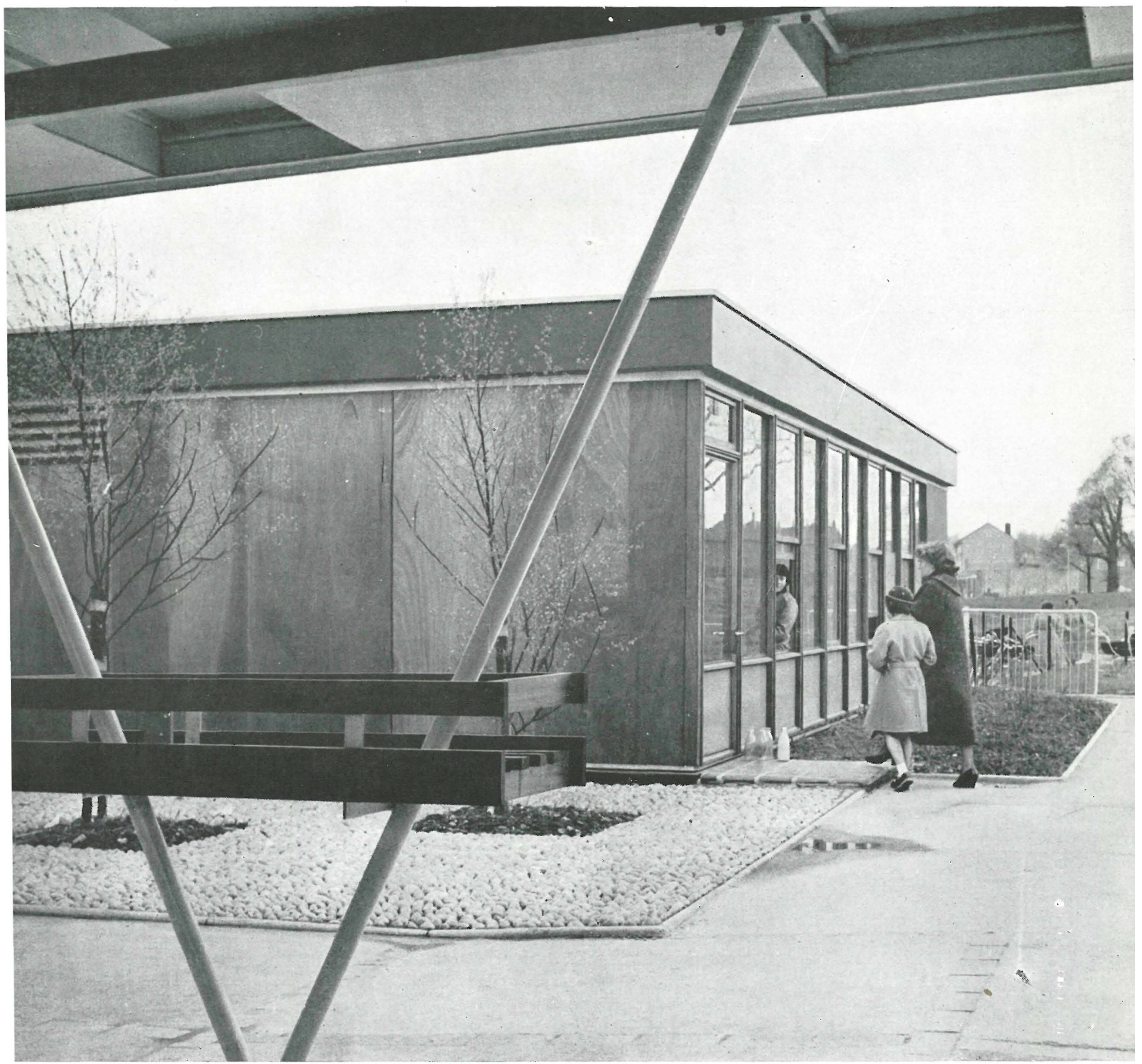

$143 \cdot 27$

\section{centro rural de asistencia médica}

C. H. ASLIN, arquitecto 

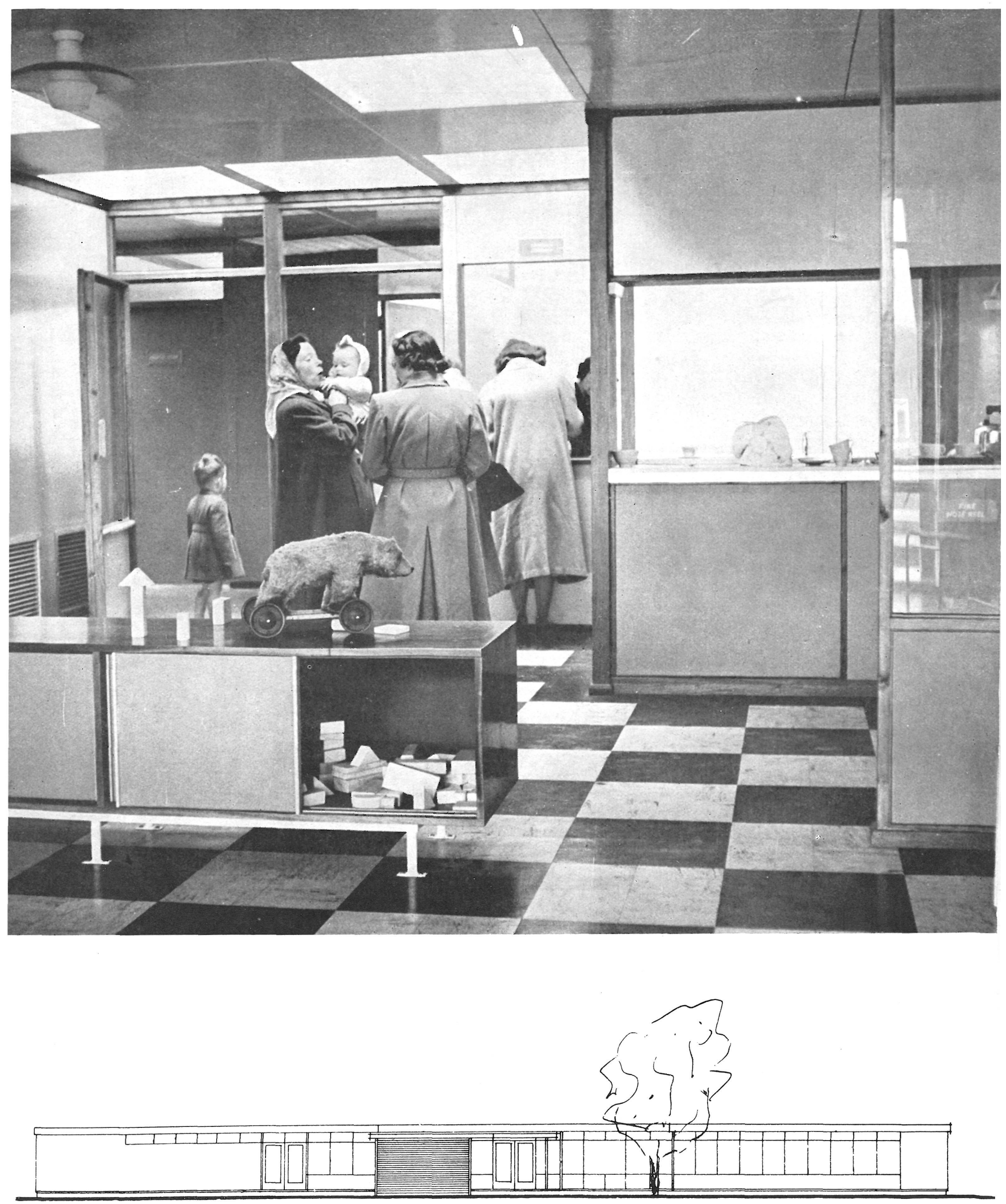
Inglaterra ha prestado en estos últimos años especial atención a la creación de nuevos centros médicos, los cuales, distribuidos por todo el país, realizan una labor de indudable mérito humanitario.

Il centro rural de asistencia médica de Hertford, pertenece al grupo de estas realizaciones. Situado en las cercanías del pueblo, se dedica a atender las necesidades del mismo y de la región vecina, estando sus instalaciones preparadas como clínica prenatal e infantil en todos sus aspectos: fisiológicos, psicológicos, terapia del lenguaje, estomatología y oftalmía, así como un centro de asistencia e investigación social.

El fin que se persigue es el de mejorar las condiciones higiénicas del campo y la salud de sus habitantes.

Este centro rural se distribuye en una sola planta, formada por dos edificios unidos por un porche, cerrado por uno de sus lados. En uno de los edificios se han situado los servicios administrativos del mismo, y, en el otro, están las distintas dependencias del centro médico propiamente dicho.

El aspecto exterior de la construcción es sencillisimo. Su clistribución interior responde a las necesidades del programa, resuclto con ampiitud.

Todo el edificio, "por fuera y por dentro", viene determinado por el sistema constructivo empleado, sistema Punt, que permitió la total construcción en un tiempo inferior a seis meses, incluida la nivelación del terreno, tiempo mitad del que hubiese sido necesario si se emplease cualquier sistema tradicional.

El sistema Punt fué creado por los ingenieros Ove Arup and Partners y construido por la C. D. Productions Limited. Sus elementos, todos ellos prefabricados, comprenden: pies derechos, vigas de cubierta, paneles de cerramiento y de división interior, y elementos especiales de enlace de esquinas, encuentros y cruces. Todo el sistema se basa en un módulo cuya amplitud es de 3 pies y 4 puigadas $(1,016 \mathrm{~m})$, y cuya reticula en planta no coarta la libertad de distribución, permitiendo luces de hasta seis módulos y altura libre de 8 pies $(2,438 \mathrm{~m})$. Todos sus elementos son ligeros, manejables y de colocación fácil y ráoida. 


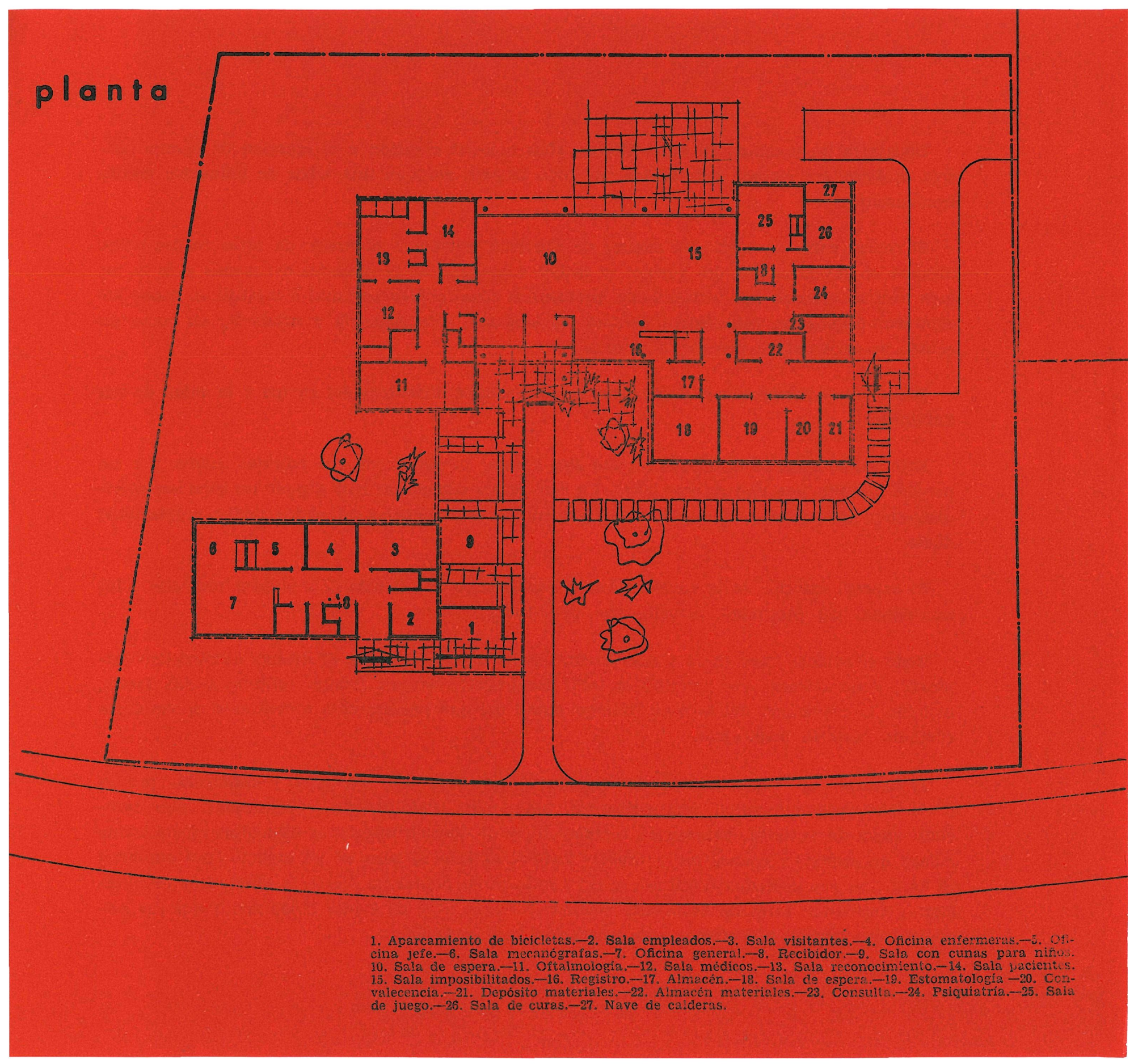



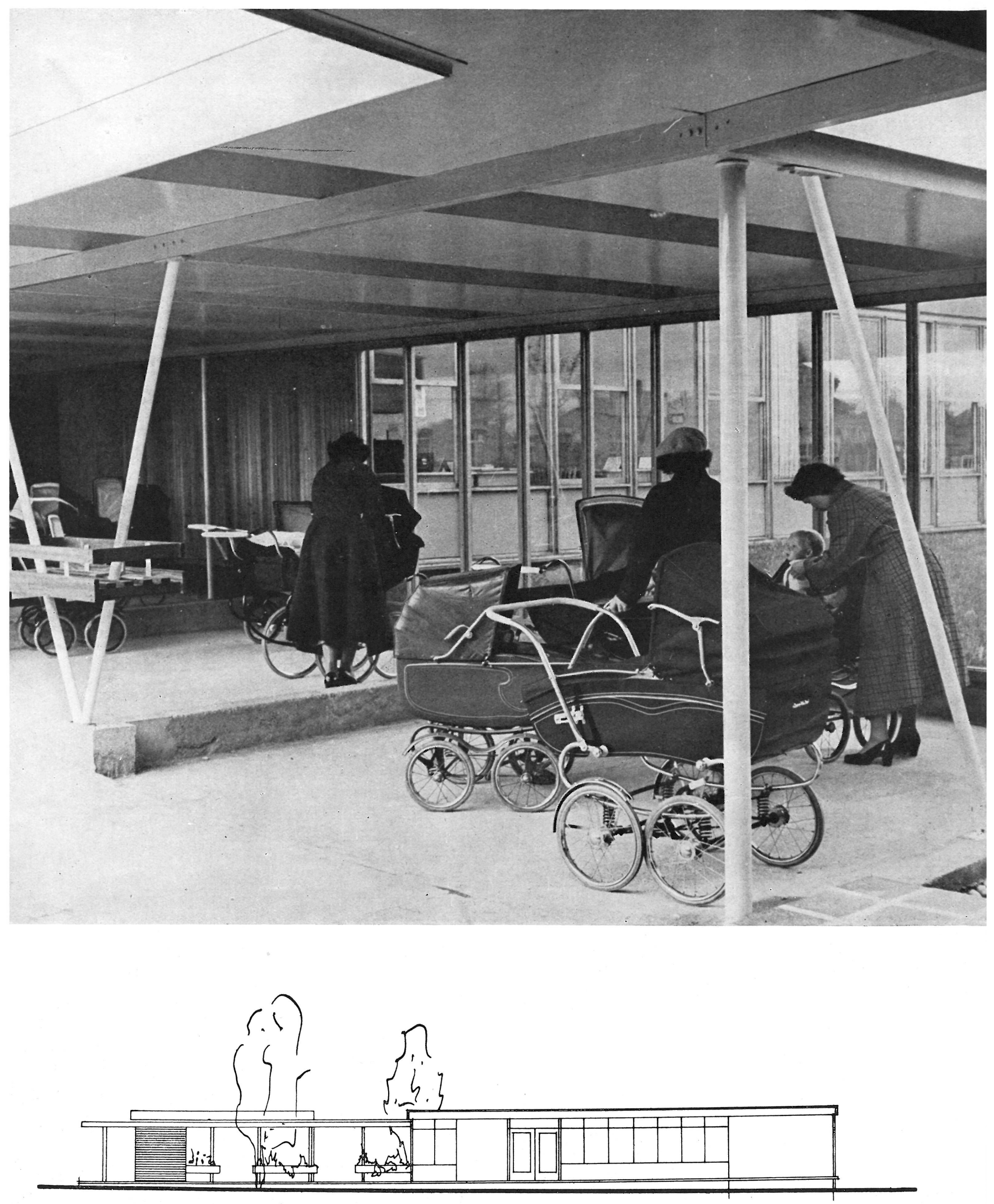


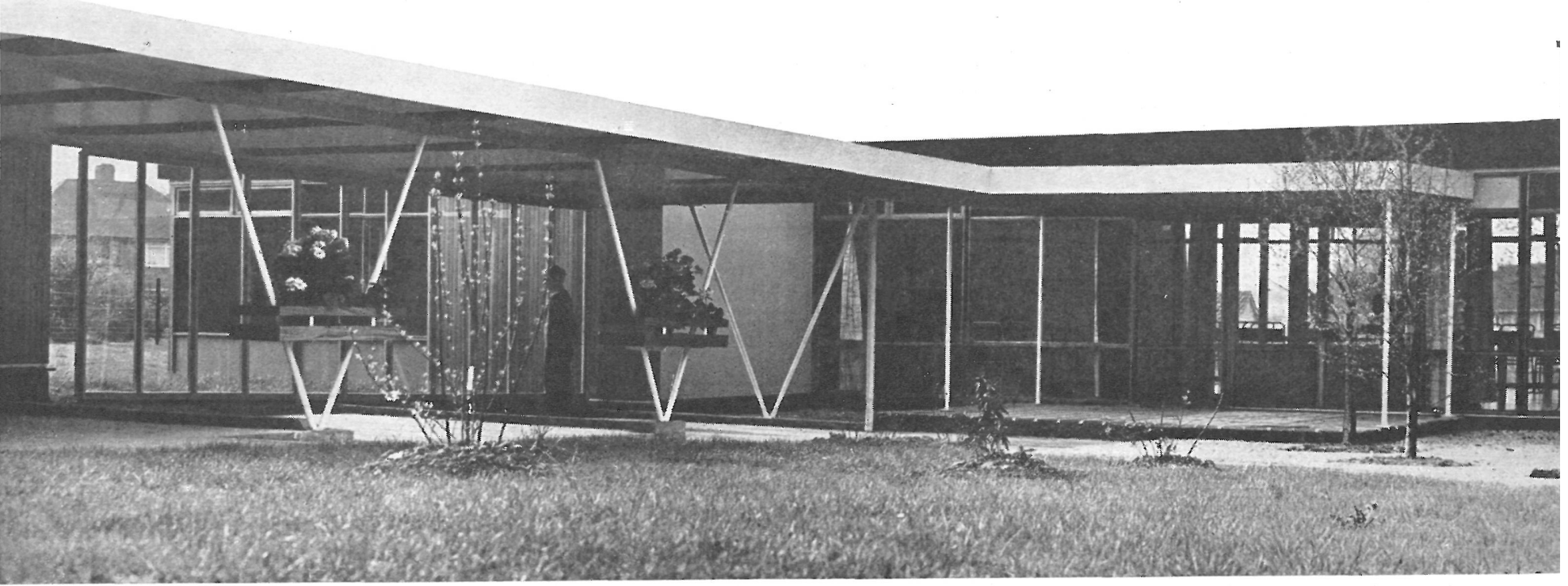

El centro rural de asistencia médica de Hertford constituye un ejemplo de construcción ligera y económica, basada en el empleo de un sistema de prefabricación ya consagrado por numerosas aplicaciones en edificaciones de una sola planta.






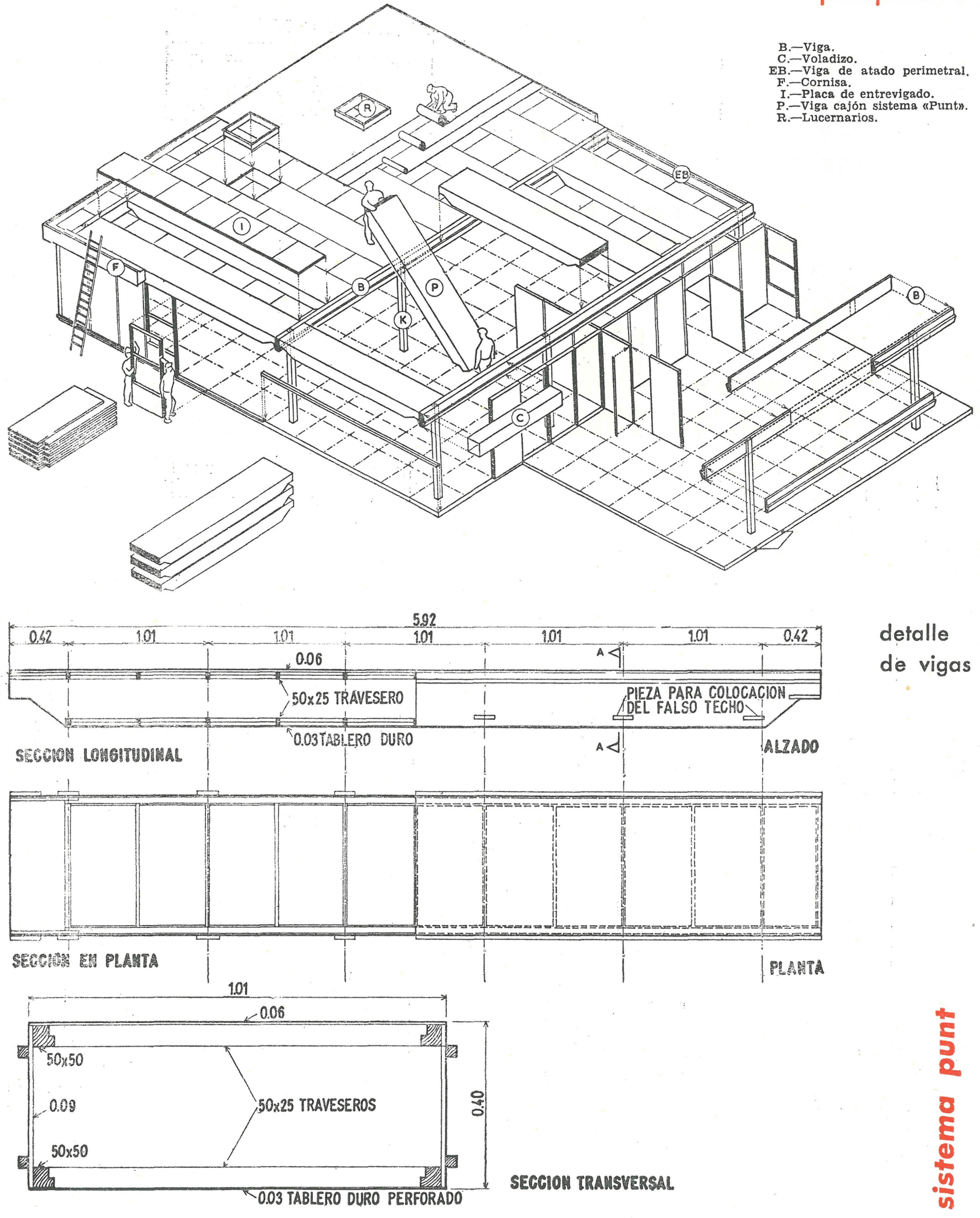

elemento 


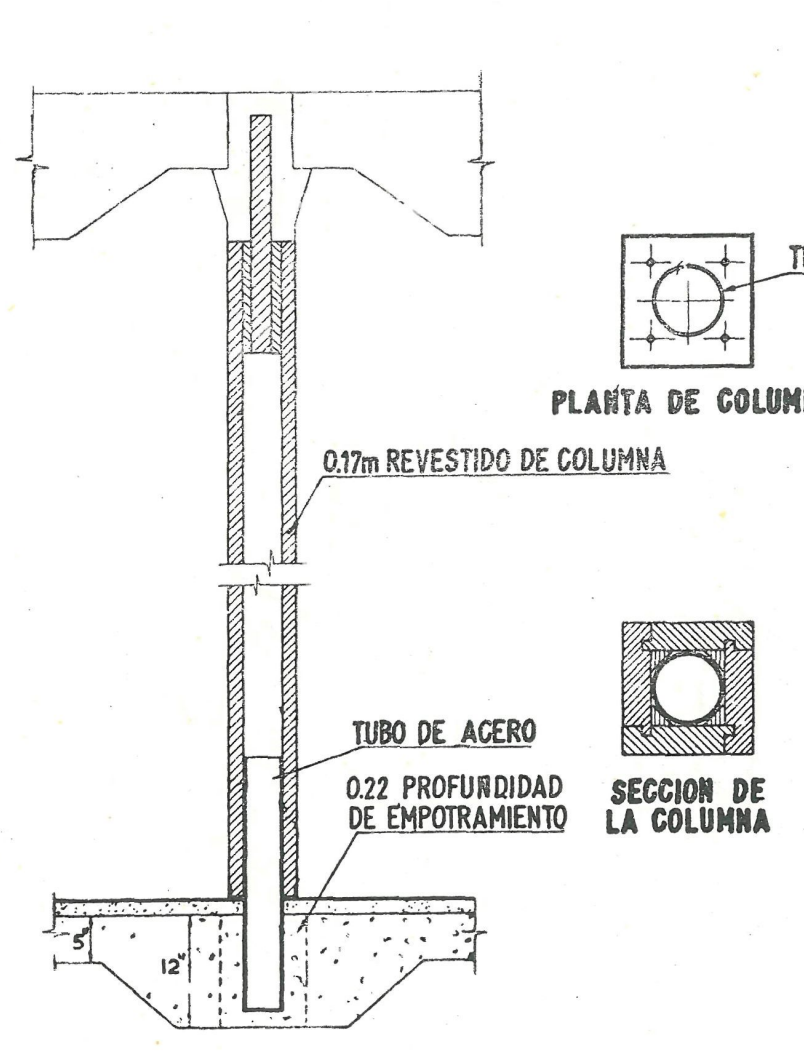

VIGA DE MADERA. LAMINADA

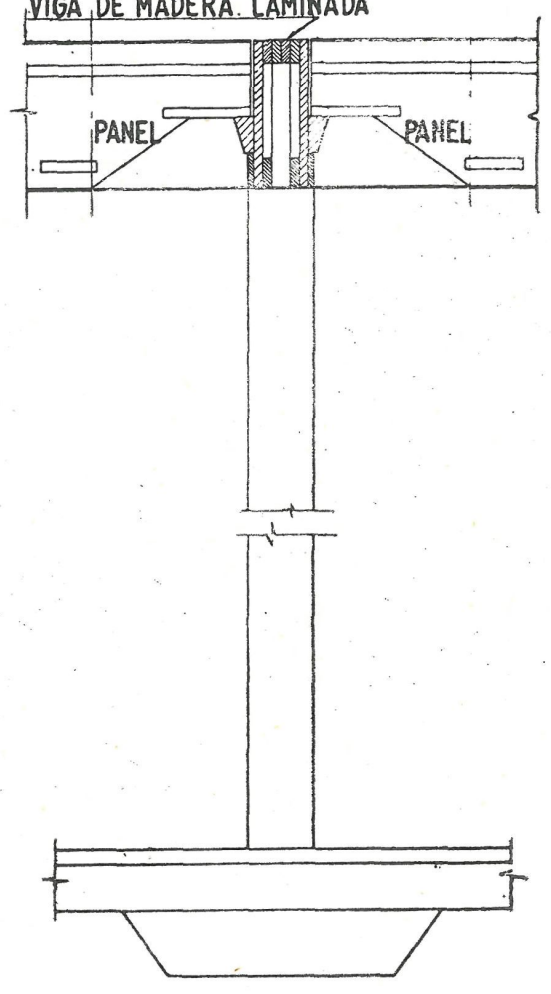

cruces y esquinas

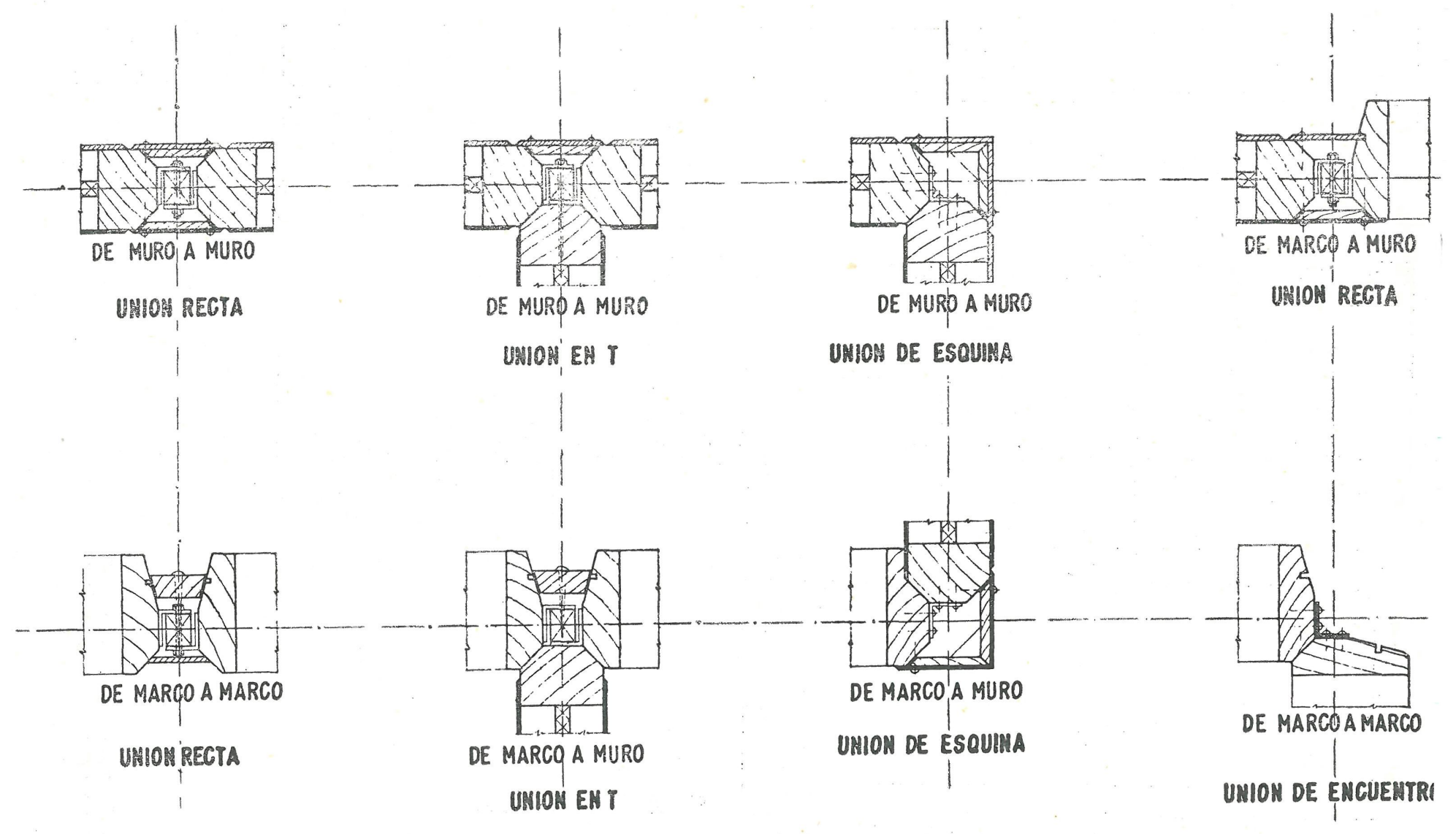

